ETD Archive

2014

\title{
Land Use and Transportation Modeling
}

Gerayeli Alireza

Cleveland State University

Follow this and additional works at: https://engagedscholarship.csuohio.edu/etdarchive

Part of the Civil and Environmental Engineering Commons

How does access to this work benefit you? Let us know!

\section{Recommended Citation}

Alireza, Gerayeli, "Land Use and Transportation Modeling" (2014). ETD Archive. 507.

https://engagedscholarship.csuohio.edu/etdarchive/507

This Thesis is brought to you for free and open access by EngagedScholarship@CSU. It has been accepted for inclusion in ETD Archive by an authorized administrator of EngagedScholarship@CSU. For more information, please contact library.es@csuohio.edu. 
LAND USE AND TRANSPORTATION MODELING

\begin{abstract}
ALIREZA GERAYELI
Bachelor of Science in Civil Engineering

Semnan University

September 2011
\end{abstract}

submitted in partial fulfillment of requirements for the degree

MASTER OF SCIENCE IN CIVIL ENGINEERING

at the

CLEVELAND STATE UNIVERSITY

December 2014 
We hereby approve thesis

Of

Alireza Gerayeli

Candidate for the Master's of Civil Engineering degree.

This thesis has been approved

For the Department of

Civil Engineering

And

\section{CLEVELAND STATE UNIVERSITY}

College of Graduate Studies by

Dr. Jacqueline M. Jenkins

Department \& Date

Dr. Stephen F. Duffy

Department \& Date

Dr. Mehdi Jalalpour

Department \& Date

$11 / 13 / 2014$

Student's Date of Defense 


\section{ACKNOWLEDGEMENTS}

This thesis was motivated by the project "The Value of Balanced Growth for Transportation" sponsored by the Ohio Department of Transportation (ODOT). As a research assistant on the project, my contributions included: 1) conducting a literature search for models quantifying the relationship between land use measures and transportation outcomes; and 2) collecting land use and transportation data from existing data sources. I received financial support from the Civil and Environmental Engineering Department, and the College of Graduate Studies at Cleveland State University.

Many individuals assisted in the success of this study. The author would like to acknowledge and thank Dr. Jacqueline M. Jenkins for all of her guidance, support, directions, and devotion to this work and Kirby Date, Kathryn Hexter, and Dr. Wendy Kellogg, for providing land use planning information, and Charles Post for providing assistance and insight in collecting data. 


\section{LAND USE AND TRANSPORTATION MODELING}

\section{ALIREZA GERAYELI}

\section{ABSTRACT}

Across the United States, the need and value of coordinated land use and transportation planning have become a highly debated topic. There are those who believe that the coordination of land use and transportation is best served in the development of compact communities with alternate modes of travel. This approach is thought to preserve natural resources and result in a reduction in the number and length of vehicle trips. Others believe that such compact developments will lead to highly congested transportation systems.

The Federal Highway Administration (FHWA) has acknowledged the need and value of coordinating land use and transportation planning, and has taken several initiatives to integrate these processes. In addition, there have been a variety of previous research efforts which investigated specific relationships between various individual land use measures and transportation outcomes. Such efforts have also included the development of various entropy values and metrics which serve to combine various land use measures. Generally speaking, compact developments, with high population and employment density, good street connectivity, and access to transit have been shown to be associated with lower vehicle miles traveled (VMT).

The objective of this thesis was to examine whether the latest published metric for evaluating the sprawl of Metropolitan Statistical Areas (MSAs) is correlated with transportation outcomes, as predicted by the relationships reported in the literature. To do 
so, a comprehensive literature review was conducted. The quantitative relationships between land use measures and transportation outcomes were extracted from the literature and catalogued. Those land use measures and transportation outcomes that were consistently found to be correlated were identified. The transportation data was extracted from the latest release of the Urban Mobility Report. Using linear regression analysis, the relationship between the latest sprawl index values and the transportation data was examined.

Based on linear regression analysis, the latest sprawl index was found to be negatively related to vehicle miles traveled (VMT), such that the vehicle miles traveled (VMT) decreased for less sprawling MSAs .The relationship suggests that those who live in less sprawling areas tend to drive less by almost 1.6 miles per day. The annual hours of travel delay was also found to be negatively related to the sprawl index, such that the annual hours of travel delay decreased for less sprawling MSAs. This relationship suggests that those people living in compact areas experience less travel delay than those in more sprawling areas. These findings agree with the results of previous studies favoring compactness over sprawl. 


\section{TABLE OF CONTENTS}

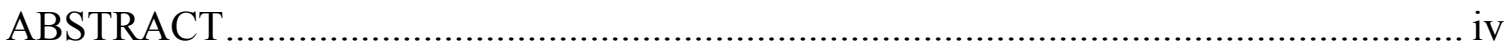

TABLE OF CONTENTS ................................................................................... vi

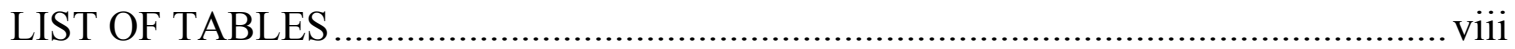

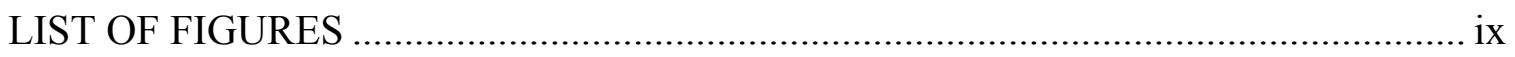

\section{CHAPTER}

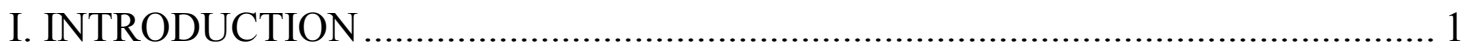

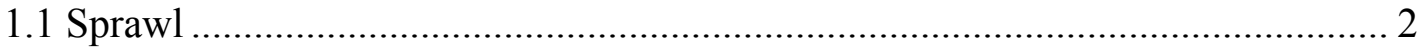

1.2 Federal Highway Administration Efforts........................................................ 3

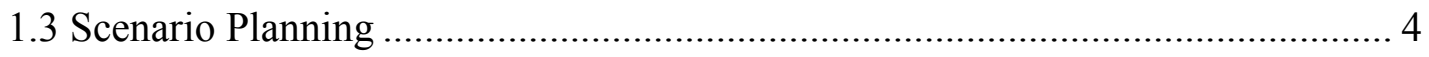

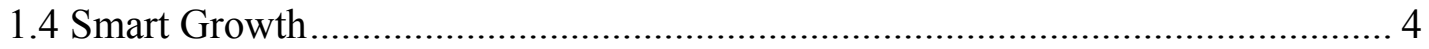

1.5 Transit-Oriented Development (TOD) .......................................................... 5

1.6 Metropolitan Statistical Area (MSA) ........................................................ 5

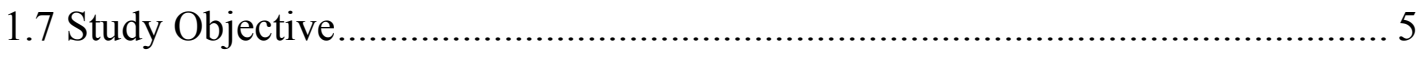

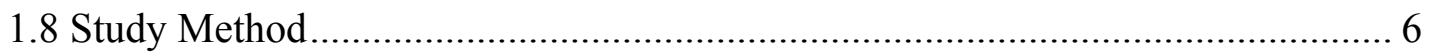

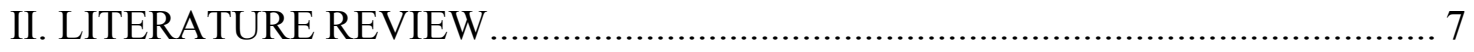

2.1 Sprawl Measures ........................................................................................ 7

2.2 Vehicle Miles Traveled (VMT) .................................................................. 10

2.3 Freight Vehicle Miles Traveled (VMT) ........................................................ 14

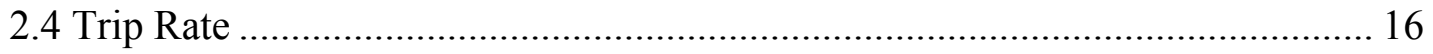

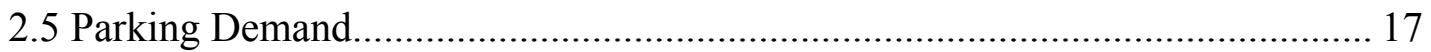

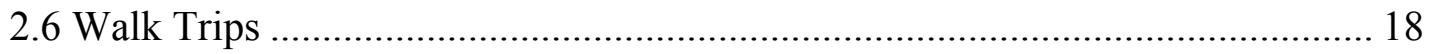


2.7 Single Occupant Vehicle (SOV) Use................................................................ 18

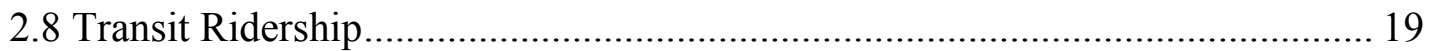

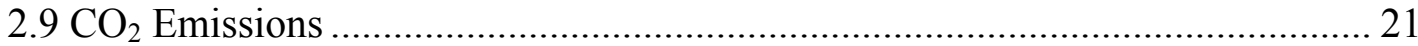

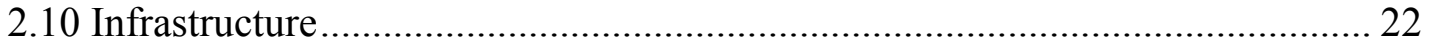

III. LAND USE - TRANSPORTATION STUDY DESIGN ………........................ 24

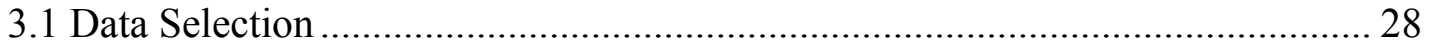

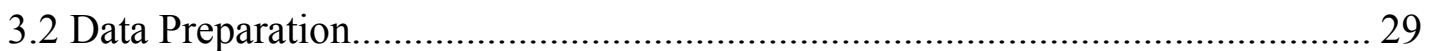

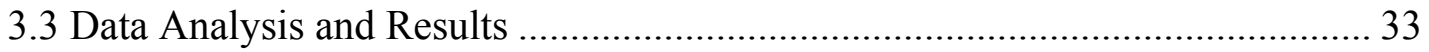

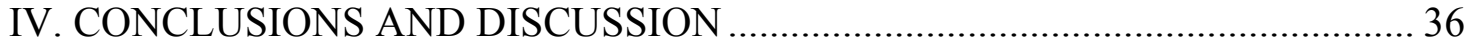

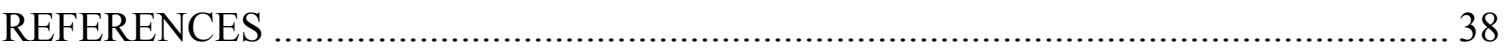




\section{LIST OF TABLES}

Table

Page

I. List of MSAs with Sprawl Index Scores and TTI Traffic Congestion Data............ 30 


\section{LIST OF FIGURES}

Figure

1. Freeway Daily VMT Per Capita in 2010 Histogram ......................................... 30

2. Normal Probability Plot of Freeway Daily VMT Per Capita in 2010 .................... 31

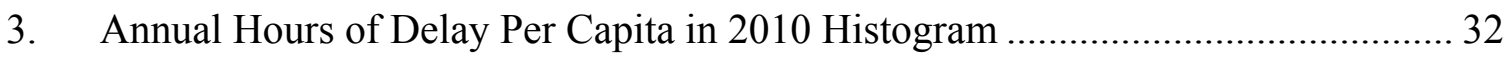

4. Normal Probability Plot of Annual Hours of Delay Per Capita in 2010 ................ 32

5. Plot of 2014 Sprawl Index Composite Score Versus The Freeway Daily VMT Per

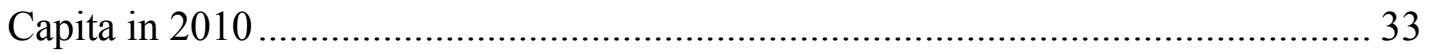

6. Plot of 2014 Sprawl Index Composite Score Versus Annual Hours of Delay Per

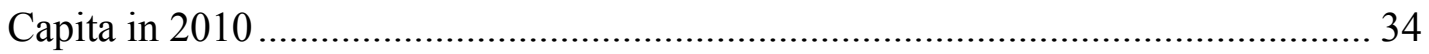




\section{CHAPTER I}

\section{INTRODUCTION}

The transportation and land use cycle describes integration of land development and the need for transportation infrastructure. As the infrastructure is improved and/or expanded, it provides greater mobility and/or accessibility to land parcels, those parcels become more available for development, increase in value, and can be identified for new land uses and ultimately developed. Such development, whether residential, industrial, commercial, etc., creates additional demand for travel. The result can be a decrease in the efficiency of the transportation services, increase in congestion, and ultimately the need for improved/expanded infrastructure.

Traditionally, decisions regarding land development and transportation infrastructure are made by different agencies and through differing processes. Hence, while transportation decision makers such as Metropolitan Planning Organizations (MPOs), State Department of Transportations (DOTs), and the US Department of Transportation mainly consider the environmental and social impacts of proposed transportation improvements, they may overlook how the transportation investment affects the land embracing the proposed development. Land use and development decisions are normally 
made by local government and in some areas are completely separated from the transportation planning process (Federal Highway Administration (FHWA), 2013).

\subsection{Sprawl}

The disparity between land use and transportation planning processes often leads to uncontrolled land development, which is typically referred to as sprawl. Sprawl is defined by the expansion of population away from central urban areas often resulting in vehicle dependent communities.

Ewing, Pendall and Chen $(2002,2003)$ characterized sprawl by the lack of density, mix of land uses, degree of centering, and street accessibility. Using principal component analysis, they consolidated 22 land use and census variables to describe these four characteristics and then combined the four into a sprawl index. The index was calculated for 83 Metropolitan Statistical Areas (MSAs). They examined the association between their sprawl index and several transportation related outcomes including vehicle ownership, commute mode choice, vehicles miles traveled per capita, traffic delay per capita, traffic fatalities per capita, and 8-h ozone levels. High values of the sprawl index represented less sprawling areas. The vehicle miles traveled (VMT) per capita data, appeared to be linearly and negatively associated with the sprawl index. A linear regression model which controlled for population, household size, percentage of the population of working age, and per capita income for each of the metropolitan areas showed the sprawl index variable to be significant at the $0.1 \%$ level of significance, meaning that less sprawling Metropolitan Statistical Area had lower vehicle miles traveled (VMT) per capita. Ewing et al. (2014) updated the sprawl index scores using 
2010 census and land use data, but have never studied its relationship with transportation outcomes.

\subsection{Federal Highway Administration Efforts}

The Federal Highway Administration (FHWA) has acknowledged the existence of an association between land use patterns and transportation, and taken different initiatives to bring these two decision-making processes together. In order to enhance the awareness about the connections between land use and transportation, the FHWA Office of Planning, Environment, and Realty in coordination of the Federal Transit Administration Office of planning have developed a course on Land Use and Transportation Coordination. Moreover, the FHWA Resource Center Planning Technical Service Team is preparing a technical briefing on Land use and Transportation Planning. This briefing is being developed in cooperation with the FHWA Office of Planning, and is meant to expand the available resources by providing an introduction to the several issues involved in this topic and links to useful publications, research and other resources (Federal Highway Administration(FHWA), 2013). Furthermore, Federal Highway Administration (FHWA) has sponsored several land development scanning programs across the nation that aim to identify the transportation related consequences of each possible land development plan. Chicago, IL, San Diego, CA, and Charlottesville, VA have been nominated as samples of successful applications of the new planning process by FHWA. All three regions have utilized some form of a computer-aided tool such as Geographic Information Systems (GIS) or a spreadsheet program to develop long range plans encompassing various feasible land development and their associated consequences. 


\subsection{Scenario Planning}

As a result of the efforts by FHWA, the scenario planning concept has been incorporated into the planning process of most states across the United States. Scenario planning is an analysis technique which involves creating, evaluating, and comparing alternative growth scenarios. The main knowledge behind scenario planning is the collection of relationships between specific land use measures and transportation outcomes. These relationships have been drawn from a body of research on the topic.

\subsection{Smart Growth}

The Federal Highway Administration (FHWA) considers smart growth as a concept best described by a set of strategies and programs that preserve natural and cultural resources through directing development to targeted locations (Federal Highway Administration(FHWA), 2014). Most of the states have implemented, or started developing plans in response to this emerging need for coordination. The common vision of these programs is to encourage policies and practices that have potential effects on reducing transportation costs at local, regional and state levels through the support of compact and focused development. It is believed that a multi-modal, interconnected and sustainable transportation system will result in reduced build, maintenance, and management costs. 


\subsection{Transit-Oriented Development (TOD)}

Transit-oriented development (TOD) is one of the most recognized forms of smart growth. TOD is a somewhat flexible concept and applied with a variety of definitions. For example, Faghri and Venigalla (2013) defined TOD as moderate to high density, mixed use development which is located near a transit station and has good pedestrian and bicycle facilities. Generally speaking, TODs are vibrant, livable communities that have compact, dense, and walkable neighborhoods centered about a high quality transit system. Well-connected streets are designed to give priority to pedestrians while accommodating bicycles, scooters and rollerblades.

\subsection{Metropolitan Statistical Area (MSA)}

A Metropolitan Statistical Area (MSA) is a geographic delineation that encompasses a core urban area of 5,000 or more population. The United States Office of Management and Budget (OMB) has defined 381 Metropolitan Statistical Areas (MSAs) for United States (United States Census Bureau, 2013).

\subsection{Study Objective}

The objective of this thesis was to examine whether the latest published metric for evaluating the sprawl of Metropolitan Statistical Areas (MSA) is correlated with transportation outcomes, as predicted by the relationships reported in the literature. 


\subsection{Study Method}

A comprehensive literature review was conducted, and the reported correlations and/or causal relations between land use and transportation were catalogued. This cataloguing took the form of an electronic matrix, developed in an Excel workbook, complete with hyperlinks to source documents. Included in the matrix was an indication of the nature of the relationship between various pairs of land use measures and transportation outcomes. Those relationships shown to be consistent were of interest for this research. The latest sprawl index values (Ewing et al., 2014) were downloaded from the Smart Growth America website (http://www.smartgrowthamerica.org/) and transportation outcome data from Urban Mobility Report (Schrank, Eisele, \& Lomax, 2012) was downloaded from the Texas A\&M Transportation Institute website (http://mobility.tamu.edu/ums/). Using linear regression analysis, the relationship between the latest sprawl index values and the transportation outcome data was examined. The potential value of this work was to verify the expected relationship of the latest sprawl index to transportation measures, and determine the consistency of this relationship over the last decade. 


\section{CHAPTER II}

\section{LITERATURE REVIEW}

Literature on sprawl, balanced growth, and smart growth and its association to transportation was gathered and reviewed, and the reported associations including causal relations or correlations were extracted and catalogued. This cataloguing took the form of an electronic matrix, developed in an Excel workbook, complete with hyperlinks to source documents. Included in the matrix was an indication of the nature of the relationship between various pairs of land use measures and transportation outcomes.

\subsection{Sprawl Measures}

Ewing et al. (2002) defined sprawl as a process in which community development outpaces population growth, and thus leads to sparse layout of residential, business and recreation centers with poor accessibility, lacking vibrant population centers such as downtowns, and limited transportation options. They recognized that previous studies which attempted to measure sprawl with a single variable or two did not produce consistent results. Therefore, Ewing, Pendall and Chen (2002, 2002, and 2003) tried to 
capture the complexity of sprawl. Ewing et al. $(2002,2003)$ studied 83 primary

metropolitan statistical areas (MSAs) in United State aimed to find sprawl signatures and its impacts on an array of transportation related outcomes. They characterized sprawl by four factors: 1) density, 2) land use mix, 3) degree of centering, and 4) street accessibility. Using principal component analysis, they consolidated 22 variables constituting these four factors. The variables were drawn from various data sources. For instance, the density factor incorporated seven variables selected from four data sources. The result was a score for each factor for each of the 83 metropolitan statistical areas (MSA). These scores were then combined and standardized for the population size of the MSAs, and each MSA received a composite score as a result. This composite score is the sprawl index. The standardization was such that the composite score has an average of 100 and a standard deviation of 25 . Scores greater than 100 indicate more compact, less sprawling areas; while scores less than 100 indicate less compact, more sprawling areas.

Ewing et al $(2002,2003)$ extract transportation system performance indices from Texas Transportation Institute's (TTI) Urban Mobility Report database for 1990 and 2000. The transportation measures selected were 1) vehicle ownership, 2) commute mode choice, 3) commute time, 4) vehicle miles travel (VMT) per capita, 4) traffic delay per capita, 5) traffic fatalities per capita, and 6) 8-h ozone level.

Using multiple regression analyses, the density factor was found to be the most significant factor impacting travel and transportation-related outcomes. The density factor was shown to be negatively correlated with vehicle ownership, VMT per capita, traffic fatalities, and maximum ozone level. Also, the density factor had a remarkable influence on increasing transit and walk modes travel shares of commuting trips. The next 
significant factor was found to be centrality factor. As the centrality improves, there is an increase in transit and walk modes shares and a decrease in annual delay per capita and traffic fatality rates. The land use mix factor was also found to be substantially influential on commute travel time and fatality, albeit exacerbating maximum ozone levels. The street accessibility factor, defined to measure how well streets are connected, was ranked last in terms of its significance in explaining the variation in the transportation variables, with somewhat unexpected impacts. For instance, average travel time for commute trips, and annual traffic delay per capita were found to be positively correlated with street factor. This is inconsistent with the common belief that better higher street connectivity is associated with shorter travel times and less delay.

From the analysis of the 2000 data, Ewing et al. (2002) concluded that sprawling areas perform less well on almost every evaluated transportation outcome. The composite score was found to be inversely correlated with VMT, vehicle ownership, traffic fatality rate, and tailpipe emissions, while directly correlated with walk, bike and transit modes shares.

However, the regression analyses for 1990 data yielded slightly different results as to which land use factor plays the most significant role in determining transportation system performance. The density factor that was found to be the most significant factor in determining travel and transportation outcomes in 2000 data abdicated its rank to the centrality factor for the 1990 data. The centrality factor found to be directly correlated with walk share of commute trips, average commute time, annual delay per capita, and VMT per capita. The two other previously defined factors, land use mix and street accessibility, were shown to have the same impact on transportation outcomes as they had shown to have in 2000 data (Ewing et al., 2003). 
The principle component analysis that Ewing et al $(2002,2003)$ conducted to consolidate 22 land use variables into factors for density, land use mix, degree of centering, and street accessibility demonstrates the complexities of sprawl. The comparison of the results of the regression analysis for 1990 and 2000 shows discrepancy as to which sprawl factor (land use measure) has the highest significance in explaining variance in travel and transportation-related outcomes. This lack of consistency necessitated the further investigation of the technical literature to identify the strongest relationship(s) collectively established by other researchers. Finding relationships in the literature that agree with Ewing et al $(2002,2003)$ will validate the integrity of the established sprawl scores, and thus will justify examining their updated sprawl index scores which were calculated using 2010 data, yet have never been related to transportation outcomes.

The following subsections in this chapter are dedicated to the quantified relationships found in the literature. These relationships are grouped by transportation outcome.

\subsection{Vehicle Miles Traveled (VMT)}

Assuming mixed land use as the key feature of smart growth, Robert Carvero and Michael Duncan (Cervero \& Duncan, 2006) assessed the effectiveness of two land use strategies in reducing vehicular travel using data from the San Francisco Bay Area. The first scenario supported the increase in proximity of jobs to housing, referred to as jobhousing balance. The second strategy, however, advocates the adjacency of retail and consumer services to residential areas. The results showed a substantial reduction of 
travel was associated with job housing balance scenario. They found that doubling of the occupationally matched job accessibility, encouraged by job-housing balance scenario, corresponded to 32.9 percent reduction in commute vehicle miles traveled (VMT) and a 33.8 percent reduction in commute vehicle hours traveled (VHT) (Cervero \& Duncan, 2006).

In a case study conducted in Los Angeles, Chicago and San Francisco, (Holtzclaw, Clear, Dittmar, Goldstein, \& Haas (2002) discovered that residential densities are significantly associated with VMT. The relationship that is in the form of an exponential decay function indicates that the change in residential density from low to moderate results in a notable decrease in VMT.

In a meta-analysis done by Carvero (2002), the mean positive elasticity of $40 \%$ for short term and $73 \%$ for long term between infrastructure supply and induced demand was found. Induced demand is a phenomenon that describes the increase in consumption due to increase in supply, such that more trips occur because additional infrastructure is provided. Their results show that an average increase of $40 \%$ in traffic is expected within less than a year of expanding infrastructure. This growth in traffic is anticipated to increase to $73 \%$ after a period of five years.

In a study commissioned by Arizona Department of Transportation, (Kuzmyak, Transportation Consultant, \& Silver Spring, 2012) a set of regression models that accounted for household vehicle ownership, total daily household VMT, and daily household work and non-work VMT was developed. The model surprisingly showed total daily VMT to be negatively correlated with vehicle ownership. However, the vehicle ownership was also negatively correlated with residential density, land use mix, and walk 
opportunities. The model also showed that non-work VMT was negatively correlated with transit accessibility and household density.

Applying the results of a conventional four-step, travel demand forecasting model, Ming Zang (2010) used traffic simulation to investigate three transit oriented development (TOD) scenarios in Austin, Texas. With TOD in place, 770 lane miles (1239.19 lane kilometers) decrease in the portion of congested roadway was estimated. Daily vehicle miles traveled (VMT) were reduced by 10 to 12 million, which was equivalent to $3.5 \%$ to $4.5 \%$ decrease in person miles traveled (PMT). Zang concluded that the successful role of transit in mitigating congestion relies heavily upon compact development. Even though no worsening of traffic congestion was estimated in any of proposed TOD corridors in the Austin case study, he suggested that transit oriented development might face worse traffic conditions as compared to non-TOD areas, when TOD expand from the basic rail-based plan to extensive rail-and-bus coverage.

In a large household survey undertaken in four settlement classes within a prime commuter corridor of the Belfast City (Northern Ireland, United Kingdom), Cooper, Donegan, \& Ryley (2002) found that gasoline consumption falls as residential density rises. Urban containment, increased density, enhanced public transport, and cycle-ways produced a $100 \%$ increase in public transit use and that the increased transit use was associated with a $13 \%$ energy reduction. Additional findings were that decreased population density was associated with increased gasoline consumption for travel and car use (VMT), concentrated employment was associated with reduced private vehicle use, and urban containment and increased density, accompanied by car restraint enhanced the use of public transport and cycle-ways. The urban containment strategy, which limited 
peripheral dispersal of density, lead to an increase in public transport share from $6 \%$ to $13.5 \%$ and a fall in mobile energy use by $13 \%$, as compared to the uncontrolled growth scenario. Cooper, Donegan, \& Ryley (2002) concluded that densification in both residential and nonresidential locations can achieve very significant reductions in mobile energy consumption in urban areas and that those in high-density areas are more likely to walk. Therefore, population densification leads to an overall travel reduction.

Zhou \& Kockelman (2009) used a gravity demand model to compare the consequences of two development scenarios with a business-as-usual alternative. The results showed both the Road Pricing and Urban Growth Boundary (UGB) scenarios were significantly effective in reducing vehicle miles traveled (VMT) by $16 \%$ and $17.2 \%$ over the study period, respectively. The authors concluded that while reduction of VMT in the road pricing scenario stemmed from shorter trips, the VMT decrease in UGB scenario was associated with shorter and fewer trips. The compact development pattern in the UGB scenario not only contributed to a decline in trip generation, but also evidenced strong potential in promoting walk and bike trips as indicated by a27\% increase in mode share.

Using micro-simulation in a study conducted in Austin, Texas, Tirumalachetty, Kockelman, \& Nichols (2013) compared five distinctive scenarios to predict carbon emissions. As expected, those two scenarios that promoted network expansion, produced the largest VMT while, road pricing and urban growth boundary policies reduced VMT. The urban growth boundary scenario proved to be the most effective with $11 \%$ reduction in GHG emissions when compared to the base condition. The road-pricing scenario 
which elevated fuel prices to $\$ 6$ per gallon and introduced a $10 \notin$ per mile toll demonstrated fewer efficacies in decreasing VMT as it lessened VMT only by $4 \%$.

Deng \& Liu (2006) studied the potential impact of housing policies on transportation infrastructure in Chinese cities. According to the directive by Chinese Central Government, $70 \%$ of new residential units should be smaller than 90 square meters (968.75 square feet). Using a conceptual analysis, the authors found a correlation between changes in housing policies limiting the maximum unit size, and housing prices along with transportation infrastructure. The results showed: 1) residential density and transport related energy consumption per capita to be negatively correlated;2) population centrality to be negatively correlated to VMT; 3) job-housing balance to be negatively correlated to VMT; 4) as urban areas sprawl further, the average travel distance increases dramatically; and 5) higher population density leads to increased transit use.

In a study focused on 58 transportation projects in California, Pansing, Schreffler, \& Sillings (1998) found that increased bike facilities can be one of the most cost-effective travel demand management (TDM) strategies for reducing vehicle trips. They also found that increased parking cost lead to reduced vehicle trips; reduced vehicle miles traveled (VMT) and reduced emissions. Expectedly, increased carpooling was found to lead to reduced vehicle trips, VMT and emissions.

\subsection{Freight Vehicle Miles Traveled (VMT)}

Freight VMT is rapidly growing across the United States. With $40 \%$ increase over the past decade, freight VMT growth overtook urban VMT by $10 \%$ over the same period (Bronzini, 2008). Brozini (2008) studied multiple metropolitan areas to shed light on the 
potential relationship between land use and freight traffic. His results showed that lowdensity development does contribute to an increase in truck VMT. This result supports the concept of smart growth, such that denser areas will reduce freight VMT. It is also notable that higher development density has much more impact on commercial VMT than freight VMT.

Additionally, Brozini's examined Southworth et al's study of 100 metropolitan areas which revealed that VMT per capita drops as population increases. Brozini explained that this could be the result of higher densities in large population areas that lead to shorter trip lengths and that the strength of this correlation is that the population explained about 75 percent of the variation in truck VMT.

Allen \& Browne (2010) studied different aspect of freight trip generation, and found the urban form to be less conducive in reducing the number of freight trips as compared to reducing personal trips. He investigated 16 urban areas in England and found some land-use measures to be influential in freight trip generation but not all. The size of the region, in term of population and area, was found to be one of the contributing factors with larger areas creating more trips. This could be explained by the fact that larger urban areas are more likely to embrace more industrial settlements, and thus produce more goods to be transported. Additionally, greater urban areas are more likely to be polycentric, and hence require goods to be transported within them. Finally, unlike personal transport that can take advantage of alternative travel mode choices such as: walk, bike, motorbike and bus, freight mode of travel to the most part is limited to merely motorized modes of transport, and therefore unable to harvest all the benefits that small growth policies brings about. 
Holguin-Veras et al. (2012) analyzed the trip generation data of 400 businesses in New York City Metropolitan area and found that the common assumption of proportionality between freight trip generation and business size, which has been the backbone of most freight trip generation calculation models, was correct for only 18 percent of the studied businesses. In other words, using constant generation rates calculated from business size variables, such as employment, was shown to be incorrect for 82 percent of the examined franchises. They concluded that the relationship between those economic factors that translate into business size with freight generation is generally strong, however, the same relationship may not be necessarily exist between business size and freight trip generation, as the generation of trips is influenced by various logistic factors as well.

\subsection{Trip Rate}

The Trip Generation Manual (ITE) is a well-respected reference for calculating number of trips generated by individual activity centers. Robert Cervero \& Arrington (2008) studied 17 transit-oriented developments and compared the observed number of vehicle trips per dwelling estimated by the ITE trip generation rates. The results showed a significant difference. On average the actual number of trips was 44 percent less than that predicted by the ITE rates. This variation was even larger during peak periods. The AM and PM peak periods were observed to be 49 and 48 percent lower than predicted, respectively. Additionally, the number of trips and residential densities were shown to be negatively correlated. Every 5 additional units per acre of a transit oriented development 
within $1 / 2$ mile of the nearest rail station was associated with almost a $15 \%$ reduction in the number of generated trips as compared to the ITE rates

\subsection{Parking Demand}

Another study, focused on transit oriented development projects, shed further light on the transportation impacts of concentrated developments. Robert Cervero, Adkins, \& Sullivan (2010) investigated the parking demand of 31 surveyed multi-family projects in the San Francisco Bay Area and Portland, Oregon. The result suggested that parking demand is 25 to 35 percent less than what was actually supplied. In most of the projects, the demand was also less than the national standards. The weighted average peak parking demand for all 31 transit oriented development projects was 4 percent below that of the ITE parking rates. In the transit oriented projects of Portland, Oregon, the weighted average peak parking generation rate was 11 percent less than ITE standard. In East Bay, San Francisco, the parking generation rate for the TOD were equal to the ITE rate. Nonetheless, further examination of the data revealed factors that can contribute to lowering the supply.

Parking demand and walking distance to stations were found to be negatively correlated. This means that well designed communities that provide short and direct pathways to transit generated less parking demand in comparison to other areas. It was also shown that transit headway is an influential factor in generating parking demand. This is because an excellent transit service, which offers high level of service as measured by small time headways, makes for a convenient and attractive mode of travel. 


\subsection{Walk Trips}

The case study conducted by Robert Cervero \& Radlsch (1995) in San Francisco Bay Area probed the question of whether neighborhood design affects the choice of travel mode. The communities of Rockridge and Lafayette were compared. These communities have similar household average income, freeway, and transit service levels but Rockridge is a more compact, mixed-use and pedestrian-friendly area than Lafayette. Rockridge was found to have a 10 percent higher share of none-automobile modes, non-work trips. Shopping trips in this pedestrian-friendly neighborhood had the highest shares of walk trips. This is somehow contradictory to the general belief that consumer shopping in heavily auto-oriented, and thus requires large number of parking spaces.

It is remarkable that the neighborhood type was a greater determinant of mode choice for non-work trips than work trips. Residents of the pedestrian-oriented community Rockridge were found to be at least three times more likely to walk to a store, a nearby restaurant, or local park than those who lived in the automobile-oriented community Lafayette.

\subsection{Single Occupant Vehicle (SOV) Use}

Frank \& Pivo (2003) probed the presence of any relationship between urban form and three choices of travel mode: 1) transit; 2) single-occupant vehicle (SOV); and 3) walk. Using regression analysis, they found a negative correlation between SOV usage and land use mix, population, and employment density. On the contrary, these land use measures were positively correlated with choosing transit and walk as modes of travel. Moreover, the relationship between mode choice and employment density was shown to be non- 
liner. There is a minimum threshold for employment density after which the increase in transit trips and decrease in SOV usage become significant. These minimum thresholds were found to be 75 employees per acre at which a remarkable increase in transit trips occurs, and between 20 to 50 employee per acre at which a significant decrease in SOV usage occurs. Finally, statistical models showed population density to play less of a role in reducing SOV usage than employment density. This could be explained by the purpose of SOV travel to be mostly associated with work.

Chen, Gong, \& Paaswell (2007) took a different approach to study the impact of density on travel mode choice decisions. Unlike the majority of previous studies that used single trips as observation units, they studied trip-chairing phenomenon while controlling for what they referred to as density confounding factors. These are residential selfselection, generalized travel cost, and transit accessibility. They analyzed a data set collected for the New York Metropolitan region, and found that employment density at the work location to be more of a contributing factor to travel mode choice than population density at the home location. They concluded that providing sufficient transit accessibility at work would have a stronger impact on people's travel behavior than creating mixed-land use communities at home.

\subsection{Transit Ridership}

Robert Cervero (1994) focused on the transit-based housing on transit ridership in California. Residents living near Bart transit service were found 5 times more likely to commute by transit than the average resident in the same city. Several studies have sought to find the critical distance greater than which the average user is not likely to use 
transit due to its remoteness. JHK and Associates (1987) found the 0.65 percent decline in ridership for every 100 feet (30.48 meters) increase in distance of the neighborhood from the rail station for the Washington's Metrorail System. Robert Cervero (1994) found the descending rate is 0.85 percent for California's rail station.

In general, the examination of data for 27 housing sites in California showed two urban form characteristics to be the most contributing factors in transit ridership: 1) Distance to rail station; and 2) Residential density. None of other neighborhood characteristics such as walking quality was found to be statically significant in predicting transit ridership as long as strong predictors such as free parking are available around rail station.

Recognizing the benefits of coordinated land use and transportation planning in developed countries such as United States, Gilat \& Sussman (2003) studied the potential effects of transit-oriented development in developing countries using Mexico City, Mexico as a case study. They analyzed the TOD-based planning scenario, and found that increased population density and increased transit accessibility lead to increased transit use. Referring to the success of the state of the practice in Curitiba, Brazil, the authors also recommended controlling the provision of parking spaces coupling with transitoriented affordable housing to escalate population density.

Stringham (1982) studied four suburban rapid transit stations in two Canadian cities and focused on finding the Impact Zone for various land uses. The Impact Zone is defined as a maximum radial distance within which an average person is prepared to walk to a transit station. The extent of transit ridership tends to decrease sharply outside of this zone. The body of research indicates an approximate distance of 1200 to 1500 feet 
(365.76 to 457.2 meters) from transitional bus stop to catch the most number of transit patrons. Stringham conducted a community survey and found the impact zone surrounding a suburban rapid transit station was up to 4000 feet (1200 meters). This is equivalent to 1200 acres of land that could be developed to reap the advantage of this effect.

It is also worthwhile to examine the cause of significant disparity between the impact zone estimated by Stringham and what has been established by previous studies. Intuitively, this could be associated with superb level of service that rapid transit provides with comparison to traditional bus, thus making it worthier mode of travel to strive for.

\section{$2.9 \mathrm{CO}_{2}$ Emissions}

Recognizing transportation as the second biggest human-made source of $\mathrm{CO}_{2}$ emissions, Wang, Khattak, \& Zhang (2012) conducted a behavioral study investigating whether common small growth traits have impacts on $\mathrm{CO}_{2}$ emissions reduction. They analyzed 15,213 household travel behavior survey data, and found household income, number of workers, and number of children younger than 16 to be positively correlated with probability of driving. The number of workers, and the number of children younger than 16, increased the probability of driving by 9 and 3 percent, respectively. Moreover, roadway length and number of cul-de-sacs surrounding a residence were also found to be positively correlated with $\mathrm{CO}_{2}$ emissions. A 0.1 mile ( 0.16 kilometer) increase in roadway was found to be correlated with 2 percent increase in $\mathrm{CO}_{2}$ emissions. As for the ratio of cul-de-sac intersections, a reduction of 10 percent in cul-de-sac was associated with a 1.4 percent decrease in $\mathrm{CO}_{2}$ emissions. Considering roadway length as an indicator 
of accessible infrastructure, this finding aligns with the results of previous studies echoing the induced impacts of expanding infrastructure on increasing vehicle miles traveled (VMT) and subsequent $\mathrm{CO}_{2}$ emissions. The absence of cul-de-sacs could also be interpreted as a measure of street connectivity, an increase of which tends to promote alternative modes of travel such as walk, bikes, and transit.

Statistically, an additional owned vehicle was found to be correlated with a 5 percent increase in $\mathrm{CO}_{2}$ emissions. An additional ten thousand dollars of income was also associated with 5 percent increase in $\mathrm{CO}_{2}$ emissions. Surprisingly, the authors found Internet usage and working from home frequencies to be positively correlated with possibility of driving. Although this might be somewhat in conflict with general belief, it could be better explained by splitting total number of trips into work and non-work trips. While increased Internet usage and working from home reduces the number of work trips, they might not preclude the user from attending to non-occupational activities.

Finally, the authors concluded the well-balanced land use mix, commonly defined by an appropriate balance between jobs and housing is correlated to 12 percent reduction in $\mathrm{CO}_{2}$ emissions.

\subsection{Infrastructure}

In order to find the potential relationship between automobile dependencies and infrastructural costs, Newman \& Kenworthy (1999) studied 37 cities in four continents around the world. Using the city's gross regional product (GRP) as an economical index, they found that the percent of transport related expenditures is positively correlated with the amount of road length per capita, and negatively correlated with transit usage. Transit 
efficiency, in terms of the relative speed in comparison to personal mode of travel, was also been identified as a contributing factor in decreasing infrastructure expenditures. Finally the data showed that the city density explains 50 percent of the variation in percent of GRP spent on passenger transport and is negatively correlated with it. Recognizing automobile dependency and uncontrolled expansion of infrastructure as signatures of sprawl, these findings are consistent with the result of previous studies echoing the consistency of the negative impacts of uncontrolled growth on transportationrelated measures and costs across the globe.

Burchell \& Galley (2003) studied the impacts of two historically opposing projected growth scenario (sprawl vs. controlled growth) for all 3100 counties in the United States and found that an overall 188,300 lane-miles of road costing up to 110 billion dollars can be saved under the controlled growth scenario over the course of 25 years. It is worthwhile to mention that the controlled growth scenario does not intend to restrict the growth but to target it to locations where natural and human-made resources can be used more efficiently. The controlled growth scenario ensures that infrastructure costs will more likely be spent on road widening or road expansion aiming to accommodate the population difference rather than to build new roads to serve new communities. 


\section{CHAPTER III}

\section{LAND USE - TRANSPORTATION STUDY DESIGN}

Reviewing the relevant literature presented in the previous chapter, several relationships between land use measures and transportation outcomes are drawn. First, transit-orientated development is associated with reductions in PM peak trip generation, parking demand, total vehicle-miles traveled (VMT), $\mathrm{CO}_{2}$ emissions, and congestion. All these favorable changes can be attributed to an increase in transit, walk and bike mode shares that transit-based growth patterns encourage. The enhanced street connectivity coupled with walkable communities and efficient transit lessens the need for the personal car, and thus elevates transit share. High population density centered about transit stations, mixed land use, and high street connectivity are key characteristics of transitoriented development. These land use measures are captured in the four sprawl index factors defined in by Ewing et al (2002, 2003).

Second, residential density and job-housing balance have consistently been found to be correlated with lower commuting VMT and VHT, higher percentage of walk trips, lower gasoline consumption, higher public transit use, and lower transport-related energy consumption per capita. As a result, it can be reasoned that communities with adequate 
population density, and appropriate job-housing balance will generate less vehicle miles traveled (VMT), and subsequently lead to less gasoline usage in comparison with conventional auto-oriented neighborhoods. Walk and bicycle friendly areas promote these modes of travel, and combine them with transit, and thus reducing transport-related energy consumption per capita. Residential density and a measure of job-housing balance was also captured in the sprawl index defined in by Ewing et al $(2002,2003)$.

Third, six studies support the notion that mixed use and urban boundary land development policies affect daily VMT, home-based work VMT, total VMT, and average total distance traveled. These policies have found to favorably reduce these transportation outcomes, and two studies confirmed the associative decline in the tailpipe emission. The land use mix factor defined by Ewing et al $(2002,2003)$ captures the diversity of land use of land use within metropolitan statistical area (MSA).

Fourth, job density was found to be negatively correlated with private vehicle use, however, two studies found the undesired impacts of increasing job density on freight VMT and associative carbon emission. The studies illustrate the importance of residential density and job-housing balance as influential land use measures in determining transportation outcomes. These land use measures are captured in the density and land use mix factors developed by Ewing et al $(2002,2003)$.

Fifth, the literature clearly supports the effect of transit accessibility in improving transportation outcomes in favor of communities' health and welfare. Ten studies found transit accessibility to be the influencing factor in reducing different forms of VMT, enhancing public transport use and transit mode shares as the substitutive solution. Improved and expanded bicycle trails has also been found consequential in increasing 
transit usage. Transit accessibility is not directly estimated in any of Ewing et al (2002, 2003) factors; however, Ewing et al's $(2002,2003)$ degree of centering and street accessibility factors collectively capture land use measures that lead to enhanced transit accessibility. While street accessibility factor measures block length and the extent to which streets are interconnected, degree of centering factor captures the presence of activity centers such as downtowns and city centers. Increase in street accessibility and degree of centering factors is believed to support broader mode choice multipurpose trip making.

Six, compact development and high population and employment densities, which are signatures of smart growth, were found to be negatively correlated with VMT, number of trips, lane-miles of infrastructure, associative costs, and subsequent emissions. This finding was consistent across nineteen studies which investigated the potential impacts of these measures or their surrogates on transportation outcomes Increased population density coupled with increased employment density promotes public transport use and results in a drop in the single occupant vehicle mode share. In summary, compact development results in more public transit use and less energy consumption and $\mathrm{CO} 2$ emissions, while urban sprawl leads to more passenger cartrips, higher average travel distances, aggravated congestion, and inflated road infrastructure costs. The extent of compactness is captured in seven variables that Ewing et al $(2002,2003)$ consolidated to calculate their density factor.

Seventh, socioeconomic variables such as household income, vehicle ownership and number of employed individuals per household were found to be positively correlated with the number of trips, and $\mathrm{CO} 2$ emissions. Only one study unexpectedly showed a 
negative correlation between vehicles ownership and VMT, the result of which should be verified by further studies. These socioeconomic variables were controlled for in the sprawl index developed by Ewing et al $(2002,2003)$.

Finally, one study found infrastructure expansion to generate more trips and raise VMT. This relationship is consistent with the concept of induced demand, which assumed that the uncontrolled increase of supply results in the production of unprecedented travel demand.

In summary, the literature review and evaluation of the extracted relationships between land use measures and transportation outcomes leads to the conclusion that Ewing et al. (2002) sprawl index is valid and in agreement with the technical literature. Even though none of the reviewed studies has operationalized sprawl by capturing all of its facets, by piecing the extracted relationships together, the author is convinced that the overall picture described in the literature is very much similar to what has been incorporated in the Ewing et al. (2002) sprawl index. Indeed, Ewing et al. (2002) demonstrated that those who live in MSAs with low values of their sprawl index drive more, have more vehicles per household, inhale polluted air, and are more likely to have fatal accidents. At the same time, the percent of commuters with walk, bike or transit are significantly less in these MSAs.

With the release of the 2010 census data, Ewing et al (2014) updated their sprawl index by revising some of the variables consolidated in their density, land use mix, degree of centering, and street accessibility, factors. However, they have not studied the relationship of the updated sprawl scores with transportation outcomes. Therefore, the purpose of this thesis was to examine whether the latest sprawl index values are 
correlated with transportation outcomes, as predicted by the relationships reported in the literature. Vehicle miles traveled (VMT) was selected to be the best indicator of transportation system performance. The relationship between the sprawl index values and vehicle mile traveled (VMT) is explored through a regression analysis.

The author was also interested in examining the effect of sprawl on annual hours of delay. Ewing et al. (2002) did not find any significant difference between the amounts of delay due to congestion in compact and sprawling areas. This result conflicts with the argument made by Toole (2007) that more compact areas will result in more congestion and therefore more delay being experienced by users.

\subsection{Data Selection}

The sample space was limited to the MSAs evaluated in Ewing et al's (2014) update of his sprawl index based on the 2010 census data. Very large MSAs and MSAs that span across multiple states were excluded. The remaining MSA were compared to those included in the 2012 Urban Mobility Report (Schrank et al., 2012). There were 26 matching MSAs between the two datasets. These MSAs were selected for investigation.

The Urban Mobility Report (Schrank et al., 2012) provides a variety of transportation outcome measures. Since sprawl is generally believed to increase highway VMT as commuters locate further from the central business district and incur larger commute distances and times, the freeway VMT was chosen for analysis. Additionally, the annual hours of delay was selected. Some opponents of smart growth claim that as communities become more compact, congestion will increase and users will experience greater delays in traffic. 


\subsection{Data Preparation}

The VMT and annual hours of delay data was divided by the MSA population in order to control for the expected effect of population size on travel demand. Table I shows the list of selected MSA's, and associated values for the sprawl index, freeway VMT per capita and annual hours of delay per capita.

\begin{tabular}{|c|c|c|c|}
\hline MSA Name & $\begin{array}{l}\text { Sprawl Index } \\
\text { Score }\end{array}$ & $\begin{array}{l}\text { Freeway Daily } \\
\text { VMT Per Capita }\end{array}$ & $\begin{array}{c}\text { Annual Hours } \\
\text { of Delay Per } \\
\text { Capita }\end{array}$ \\
\hline Akron $\mathrm{OH}$ & 103.15 & 9.25 & 15.81 \\
\hline Albany NY & 95.12 & 11.64 & 21.25 \\
\hline Austin TX & 102.44 & 9.41 & 28.48 \\
\hline Beaumont TX & 111.54 & 12.29 & 17.31 \\
\hline Boulder CO & 117.87 & 4.49 & 14.72 \\
\hline Bridgeport-Stamford CT-NY & 121.64 & 11.48 & 28.25 \\
\hline Buffalo NY & 106.36 & 6.61 & 20.56 \\
\hline Cleveland $\mathrm{OH}$ & 85.62 & 10.92 & 20.58 \\
\hline Colorado Springs CO & 106.33 & 7.86 & 17.85 \\
\hline Columbus $\mathrm{OH}$ & 93 & 12.54 & 27.69 \\
\hline Corpus Christi TX & 117.29 & 8.73 & 9.38 \\
\hline Dayton $\mathrm{OH}$ & 101.48 & 9.86 & 16.70 \\
\hline Eugene OR & 125.63 & 6.85 & 8.87 \\
\hline Grand Rapids MI & 79.18 & 9.09 & 16.37 \\
\hline Knoxville TN & 68.22 & 10.70 & 26.08 \\
\hline Laredo TX & 131.25 & 2.50 & 13.08 \\
\hline Little Rock AR & 76.08 & 16.78 & 17.53 \\
\hline Madison WI & 136.69 & 8.43 & 13.27 \\
\hline Milwaukee WI & 134.18 & 7.68 & 18.55 \\
\hline New Haven CT & 116.29 & 12.76 & 23.64 \\
\hline Pittsburgh PA & 95.45 & 6.68 & 26.53 \\
\hline Provo-Orem UT & 108.45 & 8.41 & 17.35 \\
\hline Salem OR & 123.35 & 6.39 & 18.67 \\
\hline Spokane WA-ID & 129.4 & 6.04 & 15.94 \\
\hline Stockton CA & 120.28 & 8.78 & 8.60 \\
\hline
\end{tabular}


Table I: List of MSAs with Sprawl Index Scores and TTI Traffic Congestion Data

The VMT per capita data for the chosen MSAs was examined to check for normality. The histogram in Figure 1 and the statistic parameters (skewness score 0.333, standard error 0.456 ) of the data indicate a trivial, but accepted positive skewness. The skewness score is both less than one, and the standard error doubled. Normal probability plot was also used to verify the results. As it can be seen in Figure 2, the data fits the line.

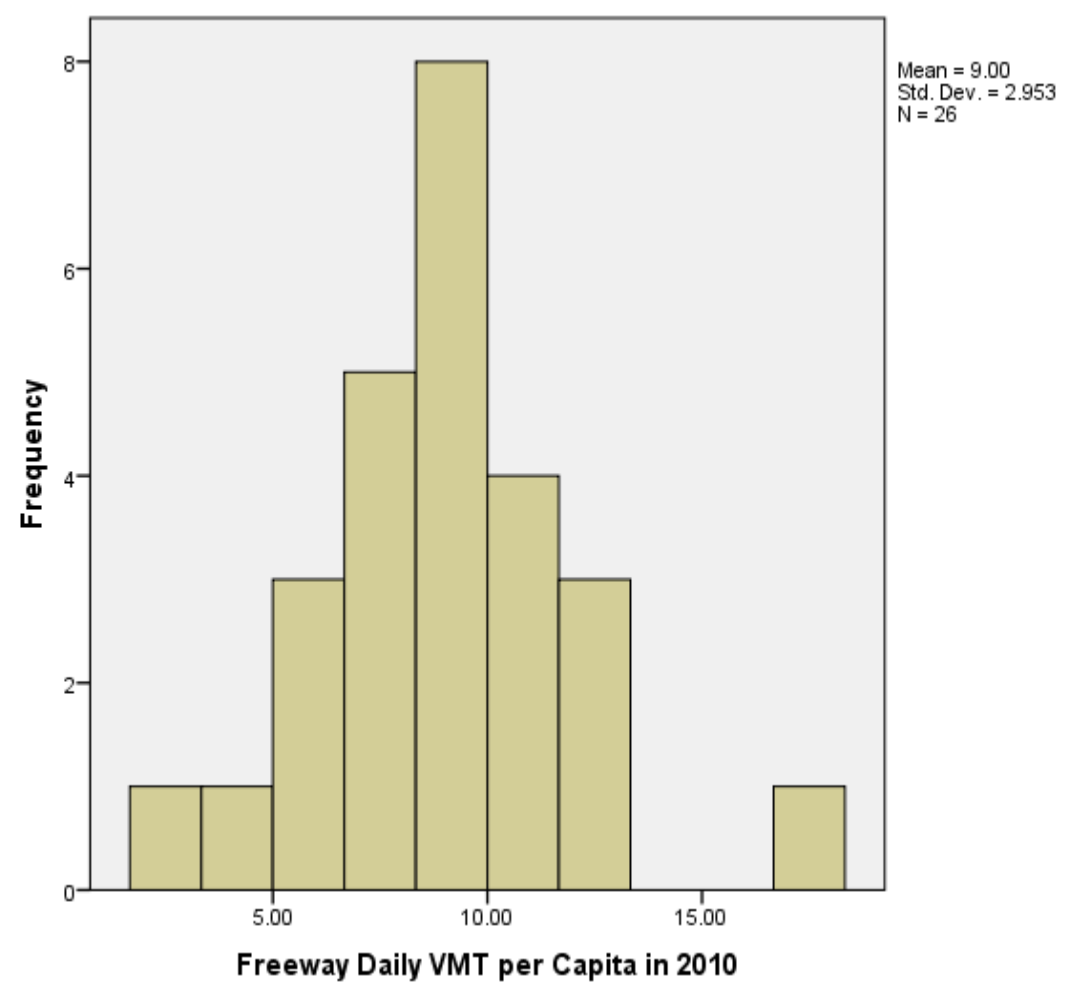

Figure 1: Freeway Daily VMT Per Capita in 2010 Histogram 


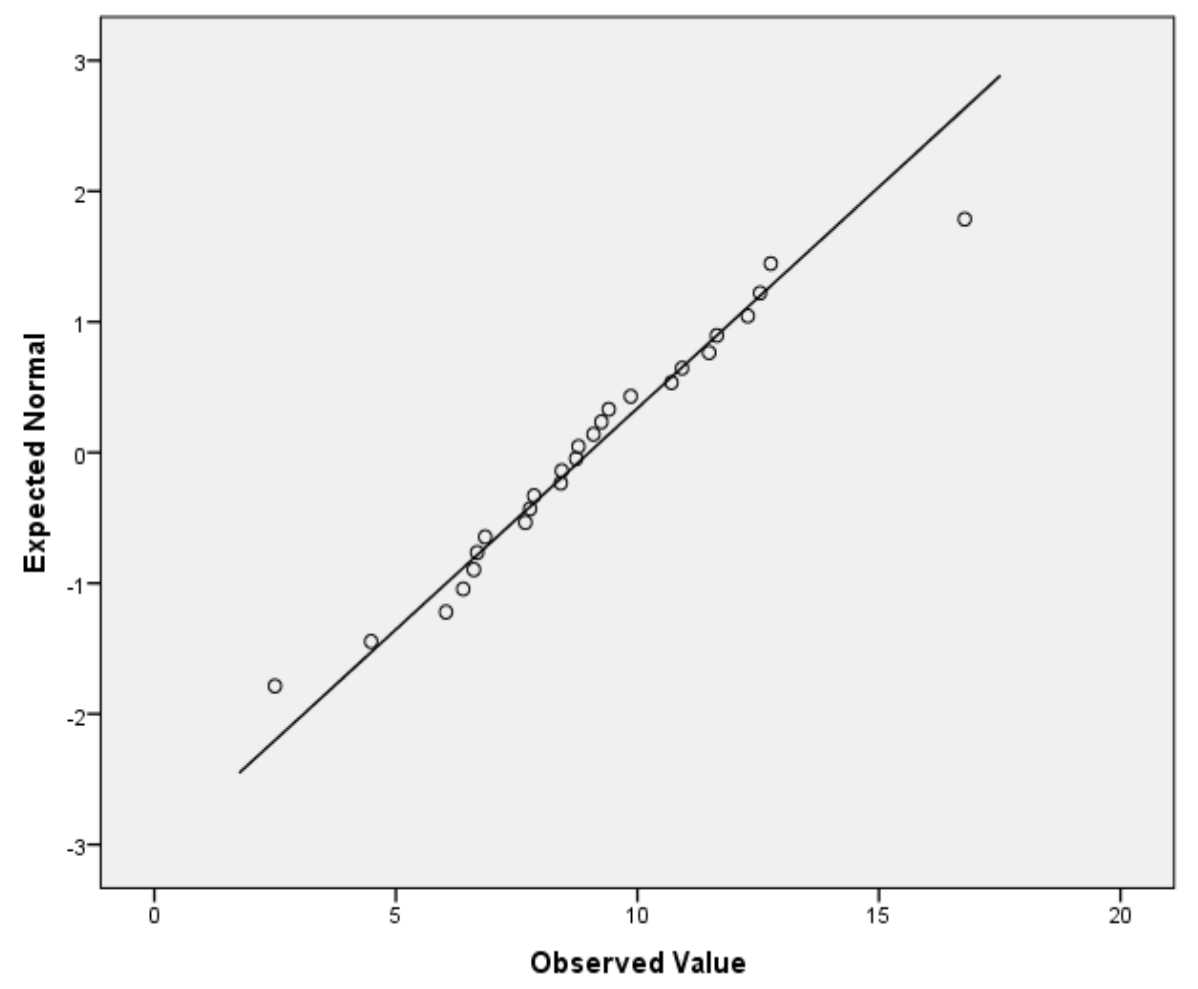

Figure 2: Normal Probability Plot of Freeway Daily VMT Per Capita in 2010

The total hours of annual delay data extracted from the Urban Mobility Report (TTI, 2012) was also controlled for population, and checked for normalcy. Figure 3 and Figure 4 show histogram and normal probability plot of the data respectively. The annual hours of delay per capita data was found to be normally distributed (skewness score 0.187 , standard error 0.456 ), and therefore did not require any transformation. 


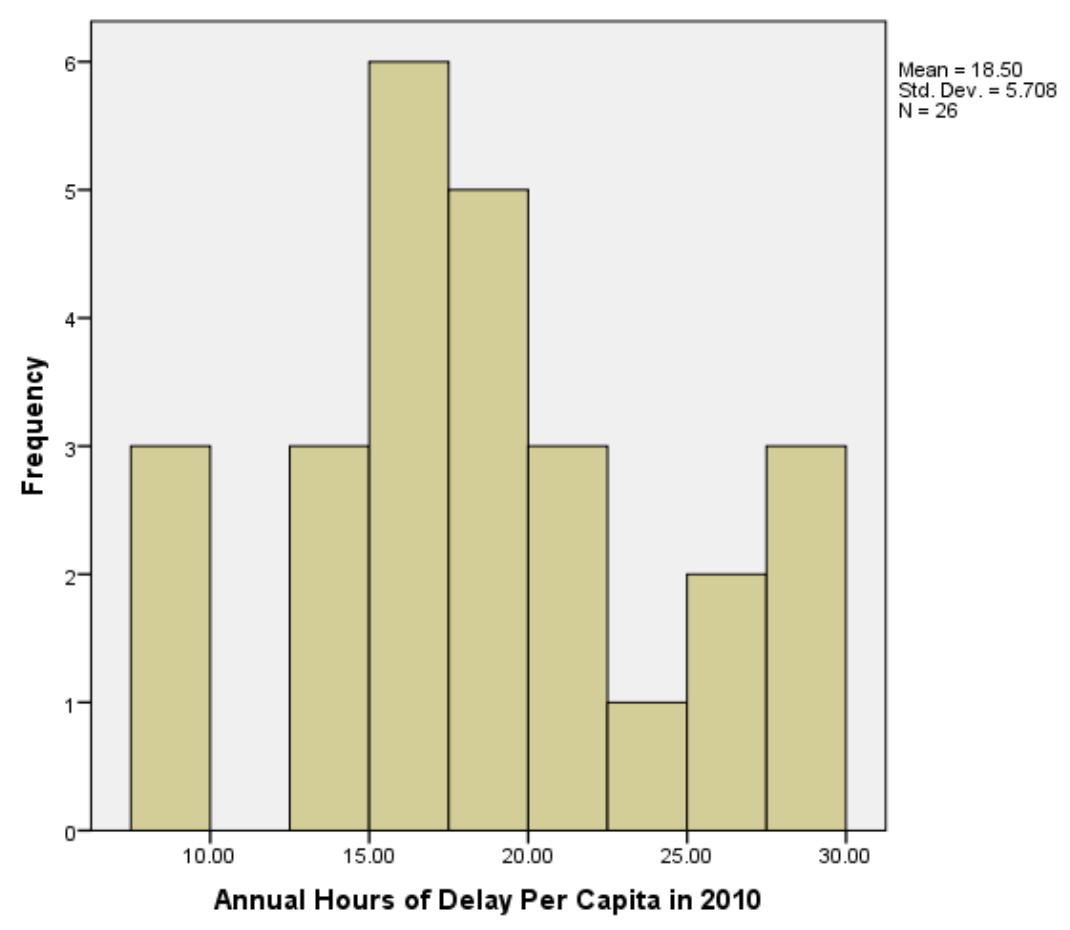

Figure 3: Annual Hours of Delay Per Capita in 2010 Histogram

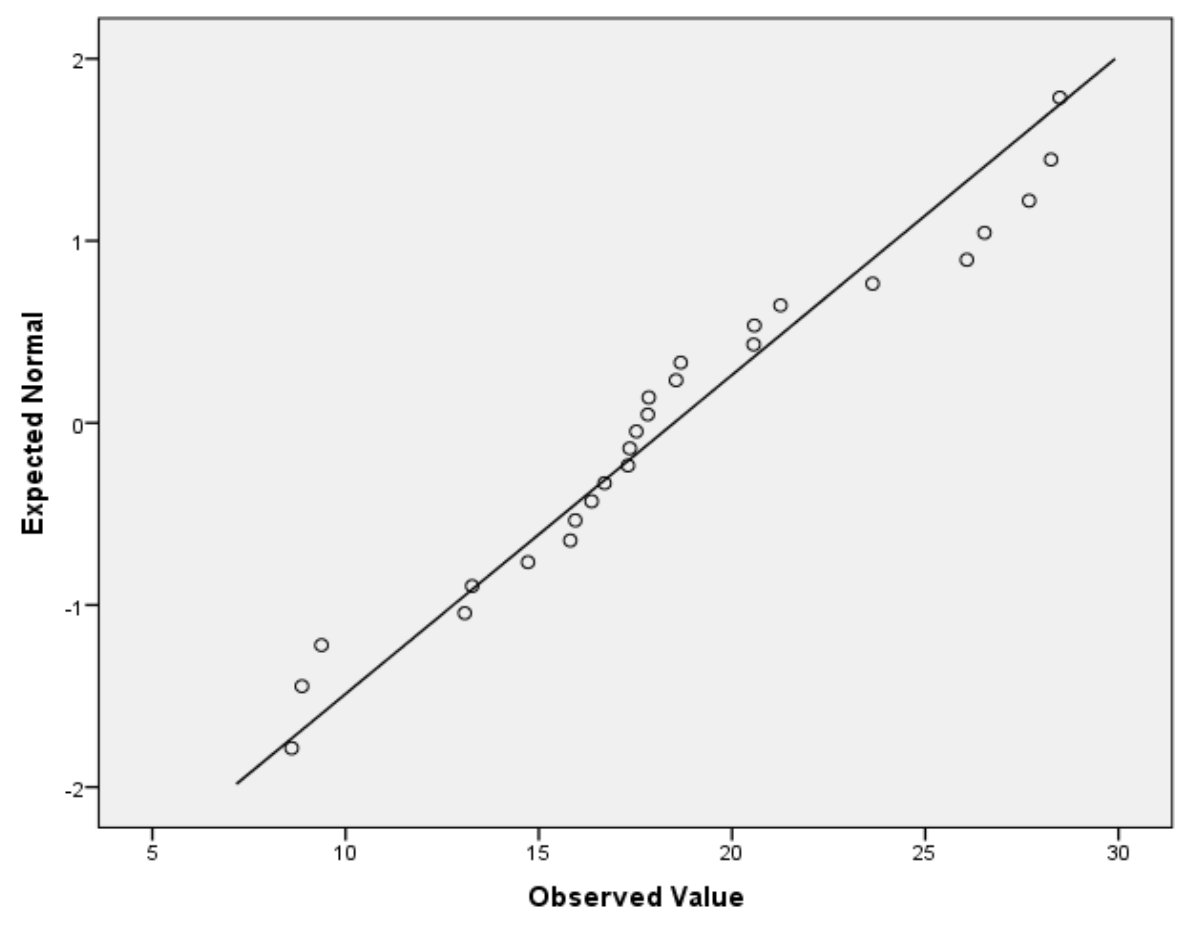

Figure 4: Normal Probability Plot of Annual Hours of Delay Per Capita in 2010 


\subsection{Data Analysis and Results}

Simple regression analysis was run to find the correlation between sprawl index values, and the freeway daily VMT per capita in 2010 . The scatter plot with a linear trend line fit to the data is shown in Figure 5.

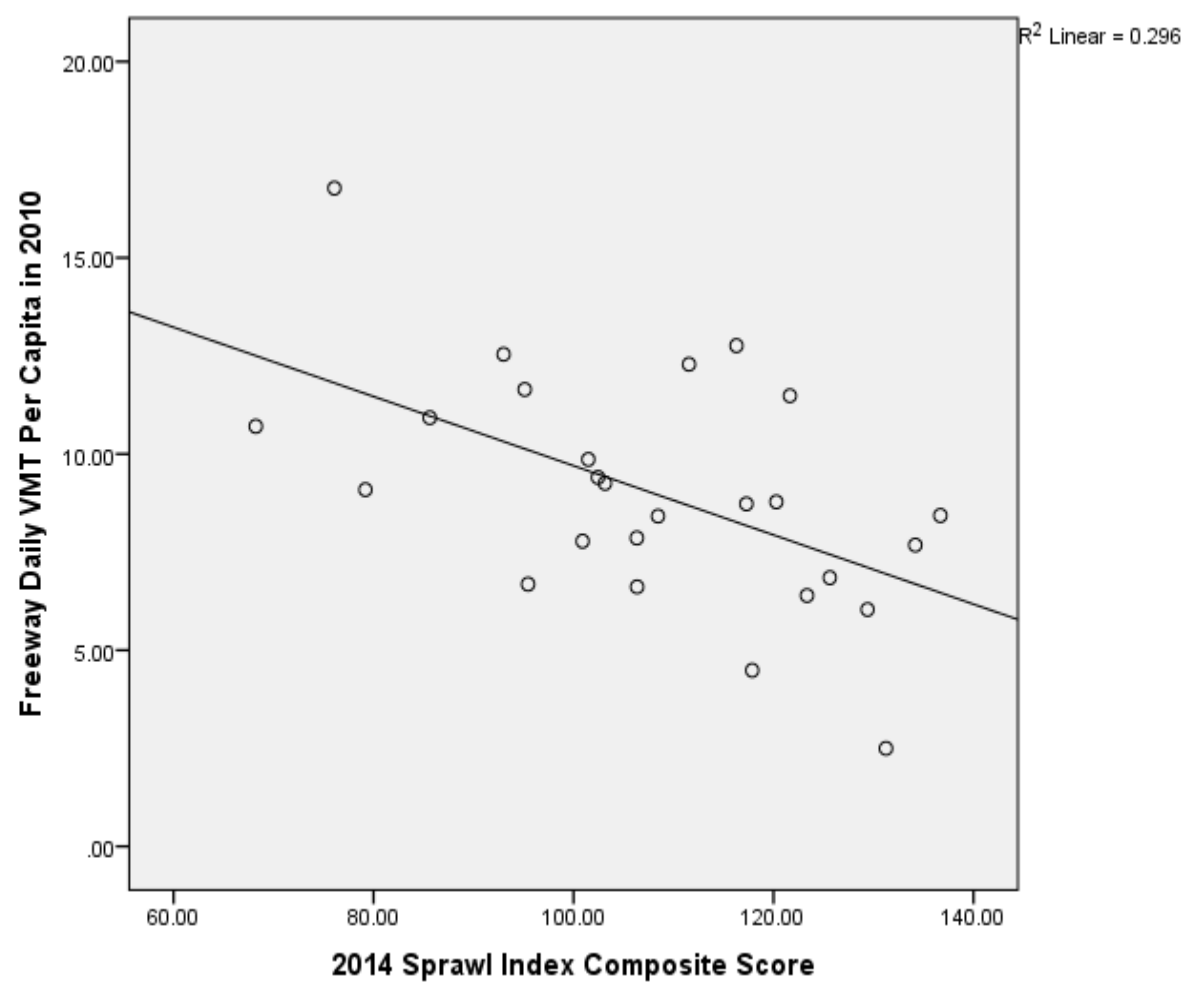

Figure 5: Plot of 2014 Sprawl Index Composite Score Versus The Freeway Daily VMT Per Capita in 2010

The results of the regression analysis are presented in equation 1 . The correlation between sprawl index and freeway daily VMT per capita found to be significant at 0.004 significant level.

$$
\mathrm{VMT}=-0.088 \times \text { Sprawl Index }+18.52
$$

The results of the regression analyses describing the relationship between the sprawl index and the freeway VMT for 2010 are consistent with that reported in the literature. 
Vehicle use was found to be inversely correlated to the degree of compactness.

According to the regression model, for every 18 units (i.e. one standard deviation)

increase in the sprawl index value, there was an almost 1.6 miles $(-0.088 \times 18.20)$ drop in daily vehicle-miles traveled per person. This result is very close to the 1.96 change found by Ewing et al. (2002) when examining the 1990 values of the sprawl index and freeway vehicle miles traveled (VMT).

Simple regression analysis was run to find the correlation between 2010 sprawl index values and annual hours of delay per capita. The scatter plot with the line fitted to the data, and regression analysis results are shown in Figure 6, and equation 2 respectively.

$$
\text { Delay Hours }=-0.136 \times \text { Sprawl Index }+33.169
$$

The correlation between sprawl index and annual Hours of Delay Per Capita in 2010 found to be significant at 0.027 significant level.

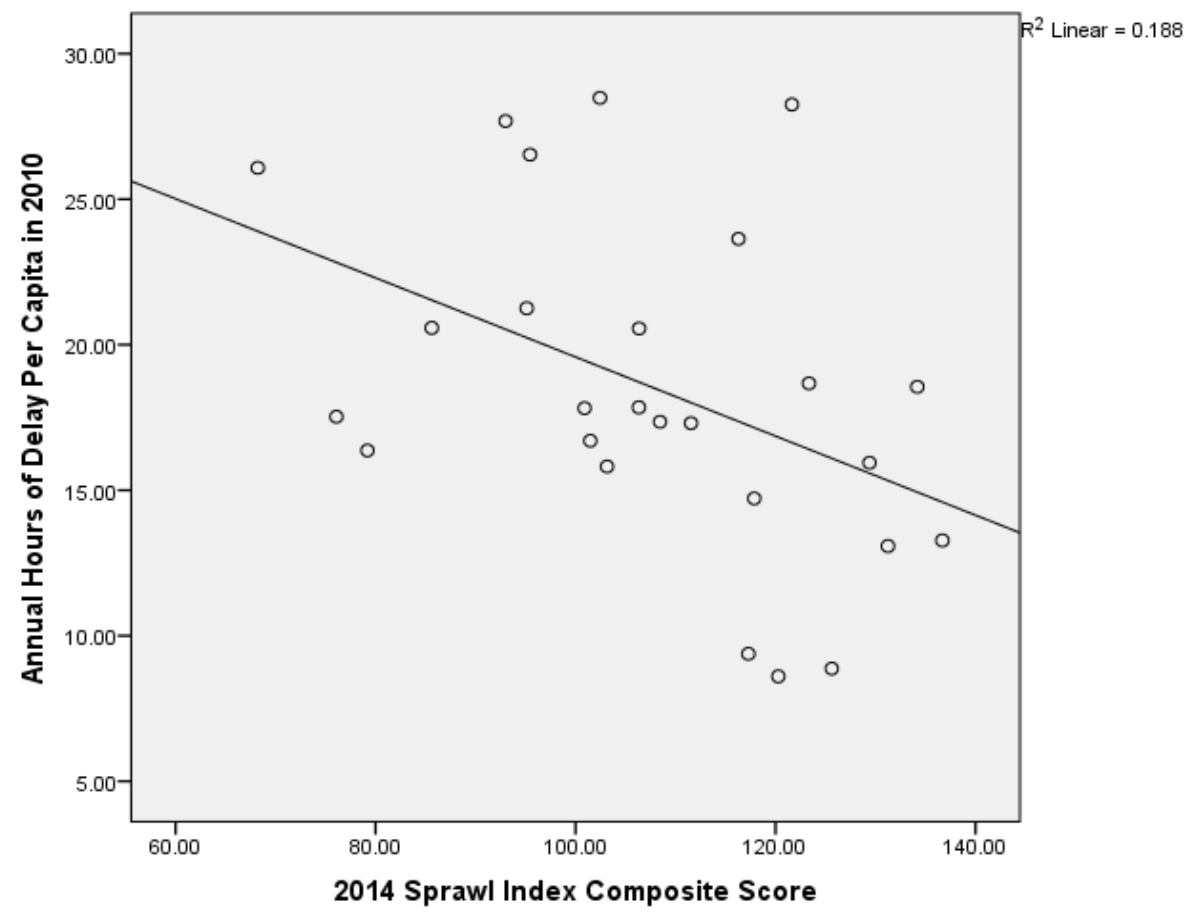

Figure 6: Plot of 2014 Sprawl Index Composite Score Versus Annual Hours of Delay Per Capita in 2010 
The results of the regression analysis describing the relationship between the sprawl index and the annual hours of delay per capita in 2010 yielded much more interesting results. For every 18 units (i.e. one standard deviation) increase in the sprawl index value, there was an almost 2.5 hours $(-0.136 \times 18.20)$ drop in annual hours of delay per person. This result contradicts the argument that compact development results in more congestion and more travel time delay per person. When Ewing et al (2002) examine this relationship with 1990 data, they found no significance correlation. 


\section{CHAPTER IV}

\section{CONCLUSIONS AND DISCUSSION}

The literature review showed an overall consensus among technical experts that land use measures are influential in altering transportation performance outcomes. The consistency in the nature of the correlations between land use measures and transportation outcomes is compelling. Transit-oriented development showed benefits to some of major transportation outcomes including vehicle-miles traveled (VMT), PM peak trip generation, parking demand, congestion, and emissions. Residential density and job-housing balance are associated with lower commuting VMT, and VHT, higher percentage of walk trips and public transport usage, and lower transport-related energy consumption per capita. Mixed land use and urban growth boundary affect daily VMT, home-based work VMT, total VMT, and average total distance traveled favorably. Increased job density is inversely related to private vehicle use, albeit two studies found it to aggravate freight VMT and associative carbon emissions. Transit accessibility was found to be influential in reducing various forms of VMT, and enhancing public transit mode share.

Compact development is the signature of smart growth. The review of literature reveals the unanimous agreement on the effects of higher population and employment densities in reducing number of trips, VMT, need for infrastructure, transportation related 
costs, and emissions. Expectedly, socioeconomic variables such as household income, vehicle ownership, and number of employed individuals per household are directly related to number of trips, and $\mathrm{CO}_{2}$ emissions. Finally, one study found the positive elasticity between infrastructure expansion and raise in VMT. However, many of the research studies were focused on examining one or two land use measures and therefore ignored the complexities of sprawl and the variety of land use measures that could account for the transportation outcome benefits.

Recognizing the complexity of sprawl, Ewing et al $(2002,2003)$ developed a sprawl index for 83 MSAs. The index was developed through principal component analysis to consolidate 22 different land use variables. Those MSAs with low values were said to be more sprawling and their transportation indices were shown to be poorer than those MSAs with high sprawl values. Ewing et al. (2014) later updated the formulation of the sprawl index, removing/replacing some of the constituent land use measures. The new sprawl metrics were not examined with respect to transportation outcomes.

A rigorous review of existing knowledge illustrates that the sprawl index (Ewing et al. 2002) is the best available measure of a collection of contributing land use variables to describe the relationship between land use and transportation. This thesis serves as an extension of the work by Ewing et al (2014). The value of this thesis is that it verifies the relationship between the 2010 sprawl index and freeway VMT per capita for 28 MSAs.

In this thesis, the relationship between the sprawl index and the annual hours of delay per capita was examined. Delay was shown to be inversely correlated to sprawl index value, meaning that those living in more compact areas had less annual hours of delay in traffic. This finding supports the concepts of smart growth and transit oriented design. 


\section{REFERENCES}

Allen, J., \& Browne, M. (2010). Considering the relationship between freight transport and urban form. Green Logistics. Retrieved from http://www.greenlogistics.org.uk/themesandoutputs/wm9/downloads/Freight transport and urban form Final September 2010.pdf

Bronzini, M. (2008). Relationships between land use and freight and commercial truck traffic in metropolitan areas. Retrieved from http://onlinepubs.trb.org/onlinepubs/sr/sr298bronzini.pdf

Burchell, R. W., \& Galley, C. C. (2003). Projecting incidence and costs of sprawl in the United States. Transportation Research Record: 1831, (03-3258), 150-157. Retrieved from http://trb.metapress.com/index/H3524N51006401W5.pdf

Cervero, R. (1994). Transit-based housing in California: evidence on ridership impacts. Transport Policy, 1(3), 174-183. doi:10.1016/0967-070X(94)90013-2

Cervero, R. (2002). Induced Travel Demand: Research Design, Empirical Evidence, and Normative Policies. Journal of Planning Literature, 17(1), 3-20. doi:10.1177/088122017001001

Cervero, R., Adkins, A., \& Sullivan, C. (2010). Are Suburban TODs Over-Parked? Journal of Public Transportation, vol. 13, No. 2, 2010 (di). Retrieved from http://ip67-88-231-156.z231-88-67.customer.algx.net/completestreets/toolkit/files/docs/JPT_Are Suburban TODs Over-Parked.pdf

Cervero, R., \& Arrington, G. (2008). Vehicle trip reduction impacts of transit-oriented housing. Journal of Public Transportation, 1-17. Retrieved from http://www.nctr.usf.edu/wp-content/uploads/2011/02/JPT11-3Cervero.pdf

Cervero, R., \& Duncan, M. (2006). Which Reduces Vehicle Travel More: Jobs-Housing Balauce or Retail-Housing Mixing? American Planning Association, 72(4), 475491.

Cervero, R., \& Radisch, C. (1995). Travel Choices in Pedestrian Versus Automobile Oriented Neighborhoods. The University of California Transportation Center, (281). 
Chen, C., Gong, H., \& Paaswell, R. (2007). Role of the built environment on mode choice decisions: additional evidence on the impact of density. Transportation, 35(3), 285-299. doi:10.1007/s11116-007-9153-5

Cooper, J., Donegan, K., \& Ryley, T. (2002). Densification and urban compaction: Reinforcing the drive for sustainability. Record: 1817, Journal of the Transportation Research Board, (02-3577), 102-109. Retrieved from $\mathrm{http}: / /$ trb.metapress.com/index/t6t5382861473872.pdf

Deng, Y., \& Liu, R. (2006). The Potential Impact of Housing Policy on Transportation Development in Chinese Cities. Transportation Research Record: Journal of the Transportation Research Board, (07).

Ewing, R., Hamidi, S., Absetz, S., Anderson, G., Berrigan, D., Chester, C., Grace, J. B. (2014). Measuring Sprawl 2014 (pp. 1-46).

Ewing, R., Pendall, R., \& Chen, D. (2003). Measuring sprawl and its transportation impacts. Record: 1831, Journal of the Transportation Research Board, (03-4195), 175-183. Retrieved from http://trb.metapress.com/index/a7926m4v4q072985.pdf

Ewing, R., Pendall, R., Chen, D., \& Smart Growth America. (2002). Measuring Sprawl and Its Impacts (pp. 1-31).

Federal Highway Administration (FHWA). (2013). Land Use and Transportation Planning.

Federal Highway Administration(FHWA). (2014). Smarth Growth \& FHWA.

Frank, L. D., \& Pivo, G. (2003). Imapcts of Mixed Use and Density On Utilization of Three Modes of Travel: Single-Occupant Vehicle, Transit, and Walking. Transportation Research Record: Journal of the Transportation Research Board, (1466). Retrieved from http://trb.metapress.com/index/a7926m4v4q072985.pdf

JHK and Associates. (1987). Development-Related Survey I.

Gilat, M., \& Sussman, J. (2003). Coordinated Transportation and Land Use Planning in the Developing World: Case of Mexico City. Transportation Research Record. doi:10.3141/1859-13

Holguin-Veras, J., Jaller, M., Destro, L., Ban, X., Lawson, C., \& Levinson, H. S. (2012). Freight Generation, Freight Trip Generation, And The Perils of Using Constant Trip Rates. Association for European Transport and Contributors, 1-22. 
Holtzclaw, J., Clear, R., Dittmar, H., Goldstein, D., \& Haas, P. (2002). Location Efficiency: Neighborhood and Socio-Economic Characteristics Determine Auto Ownership and Use - Studies in Chicago, Los Angeles and San Francisco. Transportation Planning and Technology. doi:10.1080/03081060290032033

Kuzmyak, J. R., Transportation Consultant, L., \& Silver Spring, M. (2012). Land Use and Traffic Congestion.

Namer, S. S. (2013). Optimizing Transportation Infrastructure Planning: Koya City as a Case Study. In First International Symposium On Urban Development: Koya as a Case Study (pp. 51-57).

Newman, P., \& Kenworthy, J. (1999). Costs of automobile dependence: Global Survey of Cities. Transportation Research Record: 1670, (99-1374), 17-26. Retrieved from http:/trb.metapress.com/index/D4823082069841V7.pdf

Pansing, C., Schreffler, E. N., \& Sillings, M. A. (1998). Comparative Evaluation of the Cost-Effectiveness of 58 Transportation Control Measures. Transportation Research, (98-1100), 97-104. Retrieved from http://trb.metapress.com/index/1388T6045GM523N7.pdf

Schrank, D., Eisele, B., \& Lomax, T. (2012). 2012 Urban Mobility Report.

Stringham, M. G. P. (1982). Travel Behavior Associated with Land Uses Adjacent to rapid Transit Stations. Institute of Transportation Engineer, 16-18.

Tirumalachetty, S., Kockelman, K. M., \& Nichols, B. G. (2013). Forecasting greenhouse gas emissions from urban regions: microsimulation of land use and transport patterns in Austin, Texas. Journal of Transport Geography, 33, 220-229. doi:10.1016/j.jtrangeo.2013.08.002

Toole, R. O. (2007). Debunking Portland: The City That Doesn't Work, (596).

United States Census Bureau. (2013). Metropolitan and Micropolitan Statistical Areas Main.

Wang, X., Khattak, A., \& Zhang, Y. (2012). Is Smart Growth Associated with Reductions in CO2 Emissions? Transportation Research Record: Journal of the Transportation Research Board. 
Zhang, M. (2010). Can Transit-Oriented Development Reduce Peak-Hour Congestion? Transportation Research Record: Journal of the Transportation Research Board, 2174(10.3141/2174-19), 148-155. doi:10.3141/2174-19

Zhou, B. B., \& Kockelman, K. M. (2009). TRANSPORTATION AND LAND USE POLICY ANALYSIS USING INTERGRATED TRANSPORT AND GRAVITYBASED LAND USE MODELS. Transportation Research Record: Journal of the Transportation Research Board, (2133), 123-132. 